\title{
The Archaeology of Industrialisation and the Textile Industry: The Example of Manchester and the South-western Pennine Uplands During the 18th Century (Part 2)
}

\author{
Michael Nevell
}

\begin{abstract}
Between the early 18th century and the mid-19th century the north-west of England was turned from a relatively impoverished backwater to one of the major industrialisation zones in the world. This is thus a key region for understanding the archaeology of the early stages of industrialisation. The area around Manchester was at the heart of this process, which was driven in this region by the mechanisation of the textile industry. The archaeological remains of this industrial transition are not only very extensive but also comparatively early when considered against the classic period of the Industrial Revolution; the decades either side of 1800. This paper discusses this early evidence and the results of a wide-ranging regional survey looking at the archaeology of industrialisation within the textile industry and the role of local tenant farmers in promoting industry in and around Manchester during the 18th century. It highlights a number of key sources of evidence for this period, provides a gazetteer of sites and suggests some future directions for archaeological research into the early industrialisation of this important region. The first part was published in Industrial Archaeology Review XXX.1.
\end{abstract}

\section{TeXtile Mills and the Spatial Impact OF INDUSTRIALISATION}

The first part of this paper attempted to show that there are very extensive archaeological remains, both above and below ground, for the 18th-century industrialisation of the textile industry in south-east Lancashire and north-east Cheshire; the river and upland valleys around Manchester. The most prominent part of the archaeological database are the remains of the several hundred vernacular workshops known locally as weavers' cottages, and the site of at least 387 textile mills mainly from the cotton branch of the textile industry, although woollen and silk mill sites are also represented (Figure 1).

This total includes those textiles sites, cotton spinning, fulling, wool scribbling, silk spinning mills, and finishing works (bleaching, dyeing and printing) known or still standing which were established in the 18 th century. It is thus a list of purpose-built textile sites that used either horse, water, or steam power. The list does not include the many hundreds of weaver's cottages (vernacular workshops) known to survive across the city region. Nor does it include the dozens of jenny shops recorded in the sources for towns such as Ashton-under-Lyne and Manchester, since these were frequently located in converted building.

Whilst the list is extensive, it is not comprehensive. There are notable gaps in the evidence for Wigan and parts of Bolton,
Bury, and Rochdale, for instance, whereas the boroughs of Oldham, Tameside, Trafford, Salford and Stockport and the City of Manchester have been more intensively studied (particularly in terms of the primary source material). Therefore, it is to be expected that previously unknown 18 th-century mill sites will emerge in some of the less well-studied areas, and perhaps even elsewhere. Furthermore, the upsurge in the excavation of industrial sites in the region since 2000, particularly textile sites from all branches of the industry, is only just beginning to produce published material and it can be expected that this too will add to our knowledge of the 18th-century mills of the city region.

Why and how the capital needed to build so many new structures was acquired is not a discussion archaeology can easily address, but it can help chart the development and impact of such wealth accumulation. With this in mind several points can be drawn from the evidence discussed in the first part of this paper and from the tables included below.

- The growth, archaeologically, of the textile industry can be identified before the major technical innovations of the mid-18th century. Much of this growth can be charted in the building of vernacular workshops or dedicated workshop rooms on the farmsteads of the valleys around Manchester from early in the 18th century. However, Manchester itself also retains considerable evidence for the growth 


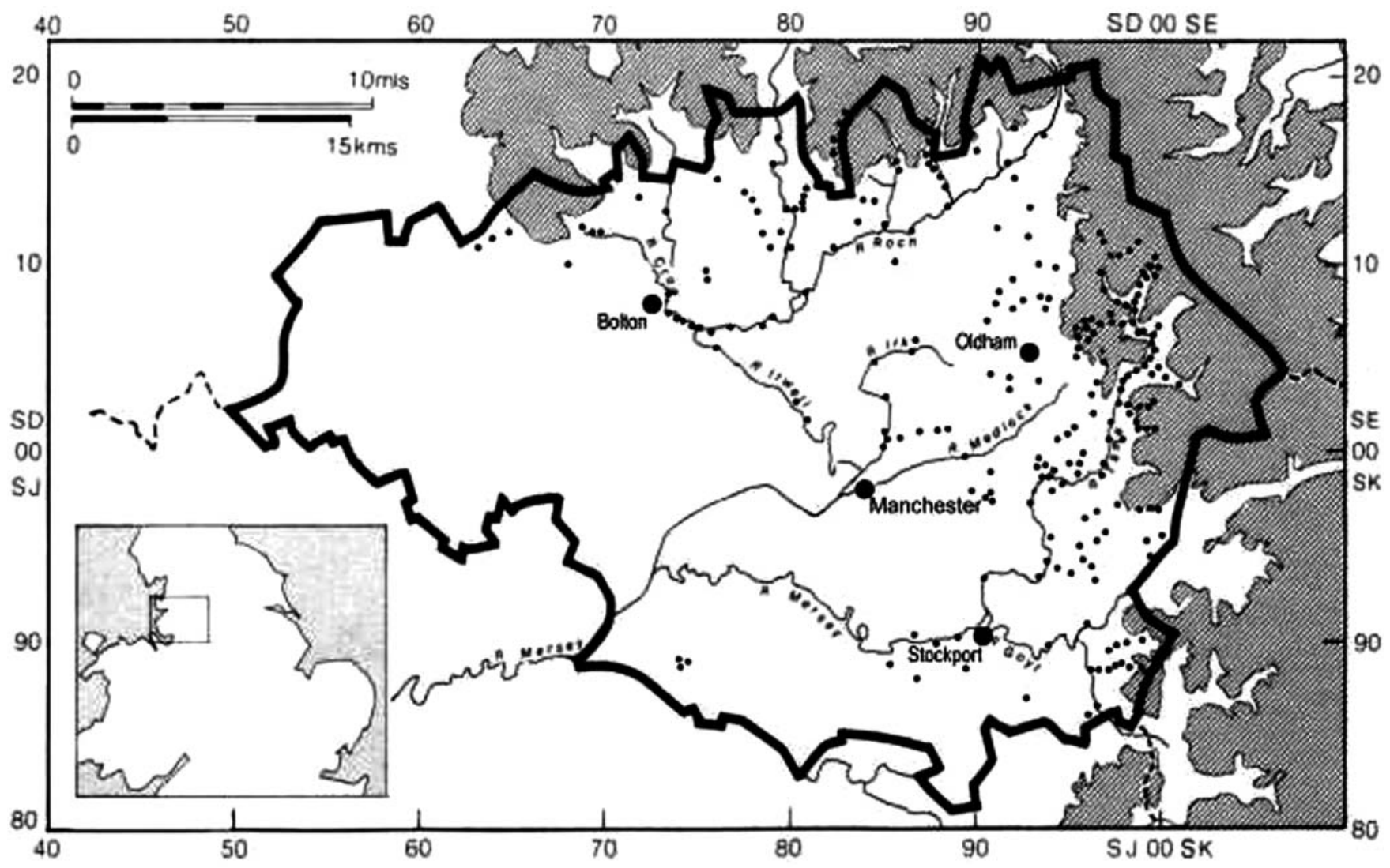

Figure 1.

18th-century mills in the Greater Manchester area.

Table 1. Breakdown of TeXtile Site Types

\begin{tabular}{lrrrrrrr}
\hline & Cotton & Wool scribbling/carding & Fulling & Finishing & Silk & Unknown/Other \\
\hline Cheshire & 39 & 0 & 0 & 0 & 26 & 2 & 67 \\
GMC & 230 & 54 & 29 & 67 & 7 & 0 & 387 \\
Lancashire & 70 & 3 & 3 & 4 & 1 & 1 & 82 \\
Merseyside & 4 & 0 & 0 & 0 & 0 & 0 & 4 \\
Total & $\mathbf{3 4 3}$ & $\mathbf{5 7}$ & $\mathbf{3 2}$ & $\mathbf{7 1}$ & $\mathbf{3 4}$ & $\mathbf{3}$ & $\mathbf{5 4 0}$ \\
\hline
\end{tabular}

Table 2. Breakdown of Textile Site Types in 18Th-Century Greater Manchester

\begin{tabular}{lcccccc}
\hline & Cotton & Wool scribbling/carding & Fulling & Finishing & Silk & Total \\
\hline Bolton & 30 & 0 & 0 & 11 & 0 & 41 \\
Bury & 12 & 0 & 2 & 10 & 0 & 24 \\
Manchester & 24 & 0 & 0 & 20 & 1 & 45 \\
Oldham & 55 & 43 & 18 & 1 & 0 & 117 \\
Rochdale & 17 & 0 & 0 & 3 & 0 & 26 \\
Salford & 6 & 0 & 0 & 10 & 0 & 16 \\
Stockport & 17 & 9 & 5 & 9 & 6 & 36 \\
Tameside & 61 & 0 & 0 & 0 & 0 & 78 \\
Trafford & 3 & 0 & 0 & 0 & 0 & 3 \\
Wigan & 5 & $\mathbf{5 4}$ & $\mathbf{2 9}$ & $\mathbf{6 7}$ & $\mathbf{7}$ & $\mathbf{3 8 7}$ \\
GMC & $\mathbf{2 3 0}$ & & & & & 5 \\
\hline
\end{tabular}

of urban-based textile production, not just redistribution and resale, from the 1740s onwards.

- Particular types of sites can be associated with particular ways of organising production; rows of workshops, whether urban-based or in the countryside, appear to be associated with merchant capital production whilst farm-based workshops and work rooms appear to be associated with artisan textile production by tenant farmers.

- Related to this is that certain types of mill may be associated with certain social groupings. This is harder to prove but the documentary evidence 
Table 3. Dates of Construction of Textile Sites in 18th-Century Greater Manchester

\begin{tabular}{|c|c|c|c|c|c|c|}
\hline & Cotton & Finishing & Scribbling & Fulling & Silk & Total \\
\hline \multicolumn{7}{|l|}{$1700-9$} \\
\hline $1710-9$ & & & & 2 & & 2 \\
\hline $1720-9$ & & & & 2 & & 2 \\
\hline $1730-9$ & & 1 & & 2 & 1 & 4 \\
\hline $1740-9$ & & 1 & & 3 & 1 & 5 \\
\hline $1750-9$ & & 3 & 1 & 5 & 3 & 12 \\
\hline $1760-9$ & & 3 & 2 & 8 & 5 & 18 \\
\hline $1770-9$ & 16 & 8 & 8 & 11 & 7 & 50 \\
\hline $1780-9$ & 89 & 30 & 28 & 25 & 7 & 159 \\
\hline 1790-9 & 230 & 67 & 54 & 29 & 7 & 365 \\
\hline
\end{tabular}

suggests that the more capital intensive water-powered cotton spinning mills (both for mule-spinning and for Arkwright's water-frame) tended to attract investment from existing landowners or merchant capitalists, whilst the small hand and horse-powered mills for jennies or mules appear to have been favoured by smaller-scale tenant farmers.

- Where there is sufficient documentary evidence to indicate the ownership or tenancy of mill sites, it suggests that their construction, or sponsorship, was primarily by individuals renting land from local landowners, and that many, perhaps the majority, of these builders were themselves established tenant farmers.

- The industrialisation of the upland valleys around Manchester appears to have been driven by ready access to the local water rights, a local population already familiar with textile skills, and above all in the availability of a reliable water supply. The latter was vital in the late 18 th century since water was the motive power needed to run the new mechanised textile machinery of the age; the spinning jenny, water-frame, and spinning mule.

- Finally, Manchester is the only urban centre in south-east Lancashire and north-east Cheshire which has archaeological remains that encompass both the vernacular workshop and all the branches of the textile industry. Indeed, by 1800 the city had at least 44 textile factories, or $11 \%$ of all of the mill sites in the Manchester area.

These observations are linked by three broader issues; access to natural resources, specialisation by process, and the comparatively early evidence for the industrialisation of the textile industry around Manchester.

Thus, the overlapping distribution patterns for the 18th-century vernacular workshops and textile mills of the region suggest that access to a reliable and plentiful water supply and an experienced labour force, so often cited as important determining factors in the location of the earliest water-powered textile mills, did indeed have a significant role to play.

Secondly, the specialisation of the textile workforce as seen in the documentary evidence for the late 17 th century appears to have had a lasting impact on both the distribution of the various branches of the textile industry around Manchester during the 18th century and in establishing the role of the local tenant farmer as an important factor in promoting proto-industrialisation and later industrialisation.

Thirdly, the physical evidence for the intensification of rural domestic textile production can now be traced to the beginning of the 18 th century, whilst the physical evidence also suggests that Manchester was already emerging as a major manufacturing, as well as marketing and redistribution centre in the early to mid-18th century, at least 40 years before the building of the first cotton spinning mill in the town. This early 18th-century evidence for industrialisation in the textile industry supports the gradualist model of industrialisation argued for by a number of economic historians and recently highlighted in the development of the Manchester Methodology by the current author and his colleagues. ${ }^{1}$

\section{CONCLUSION}

This paper emphasises once more the value of a detailed archaeological regional analysis of industrialisation in one industrial sector, emphasising the deep roots of industrialisation and the valuable role of individual monument analysis. Such archaeological evidence can provide the refined data needed to support the broader theories of industrialisation currently being debated by historic, postmedieval, and industrial archaeologists. Even so, the issues of inter and intra-regional linkages, which enabled the specialisation and industrialisation of the textile industry around Manchester during the 18th century, and particularly the role of the London markets, have yet to be fully studied archaeologically. It is only when further detailed excavation has been undertaken on the industrial sites 


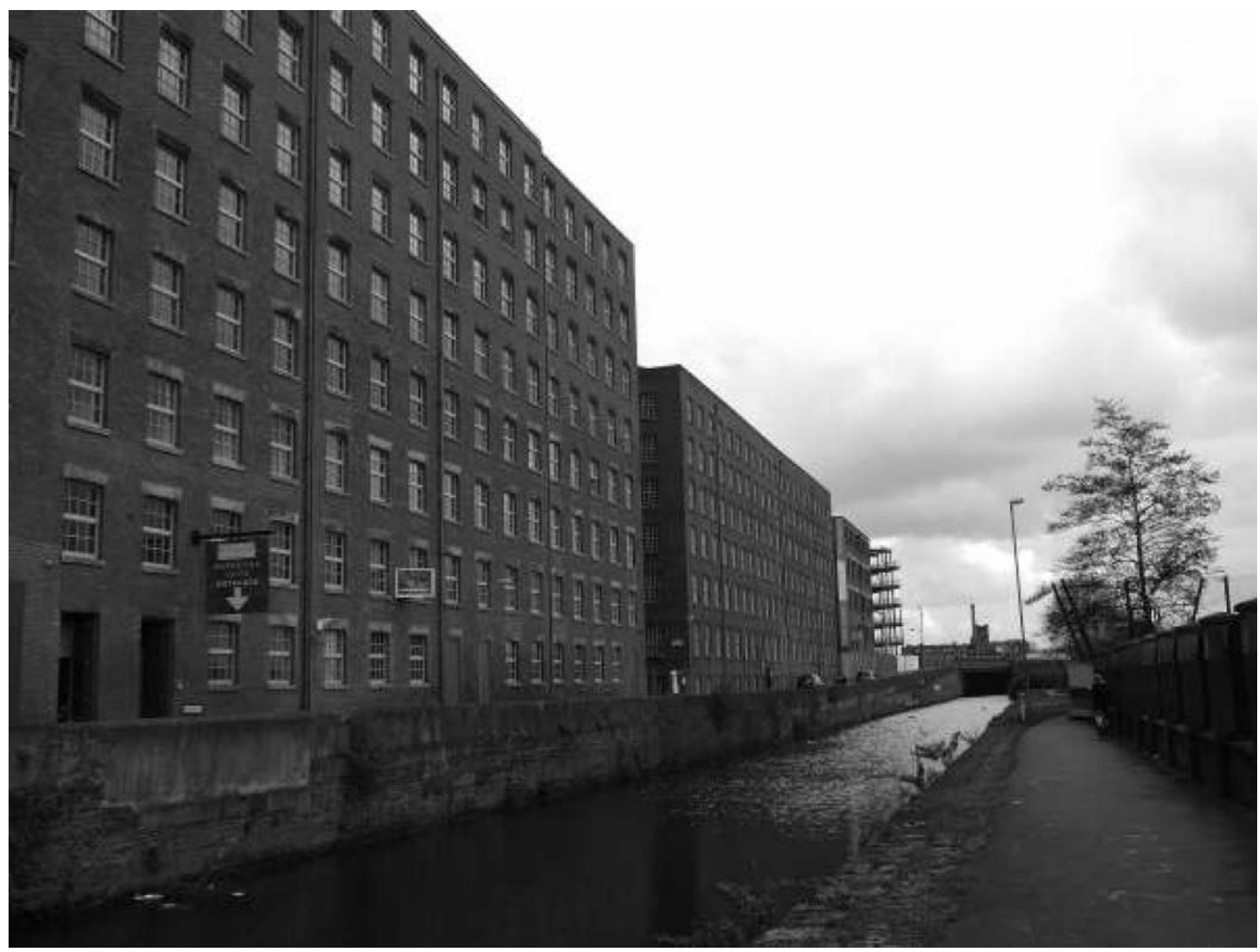

Figure 2 .

Murray's mill of 1798 on the Rochdale canal in Ancoats. of both the 18 th and 19 th centuries that we will then be able to assess fully the Manchester region's context within the national development of industrialisation.

\section{ACKNOWLEDGEMENTS}

I would like to record my thanks to Bernard and Jill Champness for their study of the archives of the Sun Insurance Company.

\section{Notes AND REFERENCES}

${ }^{1}$ Nevell, M., 'The 2005 Rolt Memorial Lecture. Industrial Archaeology or the Archaeology of Industrial Period? Models, Methodology and the Future of Industrial Archaeology', Industrial Archaeology Review, 27 (2006), 3-16.

Dr Michael Nevell is Director of the University of Manchester Archaeology Unit. Address for correspondence: School of Arts, Histories and Cultures, University of Manchester, Oxford Road, Manchester M13 9PL, UK. 